\title{
Three new $O$-isocrotonyl-3-hydroxybutyric acid congeners produced by a sea anemone-derived marine bacterium of the genus Vibrio
}

\author{
Dandan Li, Enjuro Harunari, Tao Zhou, Naoya Oku and Yasuhiro Igarashi ${ }^{*}$
}

\author{
Full Research Paper \\ Address: \\ Biotechnology Research Center and Department of Biotechnology, \\ Toyama Prefectural University, 5180 Kurokawa, Imizu, Toyama \\ 939-0398, Japan \\ Email: \\ Yasuhiro Igarashi* - yas@pu-toyama.ac.jp \\ * Corresponding author \\ Keywords: \\ 3-hydroxybutyric acid; polyhydroxyalkanoate; sea anemone; \\ Tenacibaculum maritimum; Vibrio
}

\author{
Beilstein J. Org. Chem. 2020, 16, 1869-1874. \\ doi:10.3762/bjoc. 16.154
}

Received: 23 April 2020

Accepted: 16 July 2020

Published: 29 July 2020

Associate Editor: J. S. Dickschat

(c) 2020 Li et al.; licensee Beilstein-Institut. License and terms: see end of document.

\begin{abstract}
Liquid cultures of Vibrio sp. SI9, isolated from the outer tissue of the sea anemone Radianthus crispus, was found to produce three new $O$-isocrotonyl-3-hydroxybutyric acid derivatives, $O$-isocrotonyl-3-hydroxypentanoic acid (1), $O$-isocrotonyl-3-hydroxyhexanoic acid (2), and $O$-(Z)-2-hexenoyl-3-hydroxybutyric acid (3), together with the known $O$-isocrotonyl-3-hydroxybutyric acid (4). The structures of 1-3 were established by NMR spectroscopy and mass spectrometry, coupled with anisotropy-based chiral analysis, revealing the same $R$-configuration for all congeners $\mathbf{1 - 4}$. The compounds $\mathbf{1 - 4}$ were weakly growth-inhibitory against a marine fish ulcer pathogenic bacterium, Tenacibaculum maritimum NBRC16015. Structural similarities among 1-4, the $O$-isocrotonylated 3-hydroxybutyrate oligomers $\mathbf{5}$, and microbial biopolymer polyhydroxyalkanoates (PHA) suggest the presence of a common biosynthetic machinery, and hence a possible dehydrative modification at the hydroxy terminus of PHA.
\end{abstract}

\section{Introduction}

The genus Vibrio, within the class Gammaproteobacteria, are a group of Gram-negative, halophilic, facultatively anaerobic, rod-shaped bacteria, which are motile with sheathed polar flagella [1]. This group is one of the most widespread bacterial genera of marine origin, cataloging 128 species at the time of writing [2], of which more than 12 are known to cause enteritis, marine food poisoning, bacteremia, septicemia, cellulitis, or other infectious diseases in human and aquatic animals [3,4].
Others can fix nitrogen [5], have phototrophy [6], or produce a plant hormone [7], and thus showing a higher metabolic versatility, which is also represented by 150 and more secondary metabolites discovered from this genus [8].

As part of our continuing study on the secondary metabolites of marine bacteria, Vibrio sp. SI9, isolated from the sea anemone Radianthus crispus, was found to produce a known ester $\mathbf{4}$ and 
its new congeners 1-3 (Figure 1). Compound $\mathbf{4}$ is the shortest among the five oligomers of $O$-isocrotonyl-oligo(3-hydroxybutyrate) (5) previously discovered from Vibrio [9]. In this study, we describe the isolation, structure elucidation, including the absolute configuration, and bioactivity of 1-4.

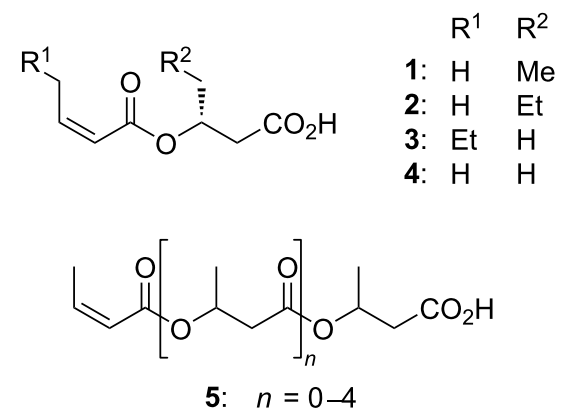

Figure 1: Structures of the compounds 1-5.

\section{Results and Discussion}

The producing strain was cultured in a sea water-based medium and then extracted with $n$ - $\mathrm{BuOH}$. The extract was successively fractionated by silica gel chromatography using a gradient of $\mathrm{MeOH}$ in $\mathrm{CHCl}_{3}$ and octadecyldimethylsilyl (ODS) flash chromatography with elution by acidic aqueous MeCN. One of the midpolar fractions was purified by reversed-phase HPLC to give $\mathbf{1}$ (1.5 mg), 2 (11.2 mg), 3 (4.3 mg), and 4 (135.6 mg) from a $3 \mathrm{~L}$ culture.
The ${ }^{1} \mathrm{H}$ NMR spectra of $\mathbf{1 - 4}$ similarly showed three deshielded resonances ( $\mathrm{H} 3, \mathrm{H} 2$ ', and $\left.\mathrm{H}^{\prime}\right)$ and a pair of mutually coupled doublet-of-doublets resonances $\left(\mathrm{H}_{2} 2\right)$, indicating a shared core structure (Table 1, Table 2, and Supporting Information File 1). In fact, the ${ }^{13} \mathrm{C}$ NMR spectra all had signals in common: two carboxy (carboxamide) and two olefinic carbon resonances along with one oxygenated carbon resonance (see Supporting Information File 1), and the analysis of an HSQC spectrum added two methyl groups and one to three aliphatic methylene groups to this composition. The molecular formula was determined to be $\mathrm{C}_{9} \mathrm{H}_{14} \mathrm{O}_{4}$ for $\mathbf{1}, \mathrm{C}_{10} \mathrm{H}_{16} \mathrm{O}_{4}$ for $\mathbf{2}$ and $\mathbf{3}$, and $\mathrm{C}_{8} \mathrm{H}_{12} \mathrm{O}_{4}$ for 4 by HRESIMS-TOF measurements, differing by a factor of one to two methylene units but giving the same three degrees of unsaturation, which are explained by two carboxy groups and one double bond. Thus, 1-4 were confirmed to be a series of acyclic compounds with a varying length of aliphatic chains.

The analysis of a COSY spectrum of the smallest congener 4 revealed two $\mathrm{C}_{3}$ fragments, $\mathrm{H}_{2} 2-\mathrm{H} 3(\mathrm{O})-\mathrm{H}_{2} 4$ and $\mathrm{H} 2{ }^{\prime}=\mathrm{H} 3{ }^{\prime}-\mathrm{H}_{3} 4^{\prime}$. The geometry at $\mathrm{C} 2$ ' was determined to be $Z$ based on a vicinal coupling constant between the olefinic protons H2' and H3' $(J=11.5 \mathrm{~Hz}$; Table 2$)$. Both of the fragments showed HMBC correlations to the same carboxy carbon $\mathrm{C} 1\left(\delta_{\mathrm{C}} 165.6\right)$, revealing an intervening ester linkage. Finally, HMBC correlations from the methylene proton $\mathrm{H}_{2} 2$ and the oxymethine proton $\mathrm{H} 3$ to the other carboxy carbon $\mathrm{C} 1$ $\left(\delta_{\mathrm{C}} 175.3\right)$ placed a carboxylic acid functionality on the methy-

Table 1: NMR data for 1 and 2 in $\mathrm{CDCl}_{3}$.

1

\begin{tabular}{|c|c|c|c|c|c|c|c|c|}
\hline no. & ${ }^{13} \mathrm{C}$ & ${ }^{1} \mathrm{H}(\mathrm{J}$ in $\mathrm{Hz})$, integral & COSY & $\mathrm{HMBC}^{\mathrm{a}}$ & ${ }^{13} \mathrm{C}$ & ${ }^{1} \mathrm{H}(\mathrm{J}$ in $\mathrm{Hz})$, integral & COSY & $\mathrm{HMBC}^{\mathrm{a}}$ \\
\hline \multicolumn{5}{|c|}{ 3-hydroxy-4-methylbutyric acid } & \multicolumn{4}{|c|}{ 4-ethyl-3-hydroxybutyric acid } \\
\hline 1 & 175.0 & & & & 176.2 & & & \\
\hline \multirow[t]{2}{*}{2} & 38.4 & $2.68, \mathrm{dd}(7.3,15.8), 1 \mathrm{H}$ & 3 & $1,3,4$ & 39.0 & $2.68, \mathrm{dd}(7.2,15.9), 1 \mathrm{H}$ & 3 & $1,3,4$ \\
\hline & & $2.61, \mathrm{dd}(5.5,15.9), 1 \mathrm{H}$ & 3 & $1,3,4$ & & $2.60, \mathrm{dd}(5.6,15.8), 1 \mathrm{H}$ & 3 & $1,3,4$ \\
\hline 3 & 70.8 & 5.22, br quint $(6.3), 1 \mathrm{H}$ & 2,4 & $1,2,4,5,1^{\prime}$ & 69.5 & $5.25, \mathrm{~m}, 1 \mathrm{H}$ & 2,4 & $1,2,4,5,1^{\prime}$ \\
\hline 4 & 26.9 & $1.71, \mathrm{~m}, 2 \mathrm{H}$ & 3,5 & $2,3,5$ & 36.1 & $1.61, \mathrm{~m}, 2 \mathrm{H}$ & 3,5 & $2,3,5,6$ \\
\hline 5 & 9.4 & $0.94, \mathrm{t}(7.4), 3 \mathrm{H}$ & 4 & 3,4 & 18.4 & $1.35, \mathrm{~m}, 2 \mathrm{H}$ & 4,6 & $3,4,6$ \\
\hline 6 & & & & & 13.8 & $0.91, \mathrm{t}(7.4), 3 \mathrm{H}$ & 5 & $3,4,5$ \\
\hline
\end{tabular}

isocrotonic acid

isocrotonic acid

\begin{tabular}{|c|c|c|c|c|c|c|c|c|}
\hline $1^{\prime}$ & 165.9 & & & & 165.8 & & & \\
\hline $2^{\prime}$ & 120.5 & $5.78, \mathrm{dq}(11.5,1.8), 1 \mathrm{H}$ & $3^{\prime}$ & $1^{\prime}, 4^{\prime}$ & 120.5 & $5.74, \mathrm{qd}(11.4,1.8), 1 \mathrm{H}$ & $3^{\prime}$ & $1^{\prime}, 4^{\prime}$ \\
\hline $3^{\prime}$ & 145.6 & $6.34, \mathrm{dq}(11.5,7.3), 1 \mathrm{H}$ & $2^{\prime}, 4^{\prime}$ & $1^{\prime}, 4^{\prime}$ & 145.5 & $6.30, \mathrm{~m}, 1 \mathrm{H}$ & $2^{\prime}, 4^{\prime}$ & $1^{\prime}, 4^{\prime}$ \\
\hline $4^{\prime}$ & 15.4 & $2.13 \mathrm{dd}(7.3,1.8) 3 \mathrm{H}$ & $3^{\prime}$ & $1^{\prime}, 2^{\prime}, 3^{\prime}$ & 15.4 & $2.10, \mathrm{dd}(7.3,1.6), 3 \mathrm{H}$ & $3^{\prime}$ & $1^{\prime}, 2^{\prime}, 3^{\prime}$ \\
\hline
\end{tabular}

a $\mathrm{HMBC}$ correlations from the proton to the indicated carbon atoms. 


\begin{tabular}{|c|c|c|c|c|c|c|c|c|}
\hline \multirow[b]{2}{*}{ no. } & \multicolumn{4}{|c|}{3} & \multicolumn{4}{|c|}{4} \\
\hline & ${ }^{13} \mathrm{C}$ & ${ }^{1} \mathrm{H}(\mathrm{J}$ in $\mathrm{Hz})$, integral & COSY & $\mathrm{HMBC}^{\mathrm{a}}$ & ${ }^{13} \mathrm{C}$ & ${ }^{1} \mathrm{H}(\mathrm{J}$ in $\mathrm{Hz})$, integral & COSY & $\mathrm{HMBC}^{\mathrm{a}}$ \\
\hline \multicolumn{5}{|c|}{ 3-hydroxybutyric acid } & \multicolumn{4}{|c|}{ 3-hydroxybutyric acid } \\
\hline 1 & 175.6 & & & & 175.4 & & & \\
\hline \multirow[t]{2}{*}{2} & 40.5 & $2.73, \mathrm{dd}(7.2,15.9), 1 \mathrm{H}$ & 3 & $1,3,4$ & 40.5 & 2.73, dd $(7.1,15.9), 1 \mathrm{H}$ & 3 & $1,3,4$ \\
\hline & & $2.56, \mathrm{dd}(5.7,15.9), 1 \mathrm{H}$ & 3 & $1,3,4$ & & $2.57, \mathrm{dd}(5.5,15.9), 1 \mathrm{H}$ & 3 & $1,3,4$ \\
\hline 3 & 66.5 & 5.30, br sept (6.3), $1 \mathrm{H}$ & 2,4 & $1,2,4,1^{\prime}$ & 66.5 & 5.32, br sept (6.3), $1 \mathrm{H}$ & 2,4 & $1,2,4,1^{\prime}$ \\
\hline 4 & 19.9 & 1.35, d (6.2), 3H & 3 & 2,3 & 19.9 & 1.35, d (6.3), 3H & 3 & 2,3 \\
\hline \multicolumn{5}{|c|}{ (Z)-2-hexenoic acid } & \multicolumn{4}{|c|}{ isocrotonic acid } \\
\hline $1^{\prime}$ & 165.6 & & & & 165.6 & & & \\
\hline $2^{\prime}$ & 109.6 & 5.73, dt $(11.6,1.6), 1 \mathrm{H}$ & $3^{\prime}$ & $1^{\prime}, 4^{\prime}$ & 120.5 & $5.76, \mathrm{dq}(11.5,1.6), 1 \mathrm{H}$ & $3^{\prime}$ & $1^{\prime}, 4^{\prime}$ \\
\hline $3^{\prime}$ & 150.9 & 6.23, dt $(11.5,7.5), 1 \mathrm{H}$ & $2^{\prime}, 4^{\prime}$ & $1^{\prime}, 4^{\prime}, 5^{\prime}$ & 145.5 & $6.33, \mathrm{dq}(11.5,7.3), 1 \mathrm{H}$ & $2^{\prime}, 4^{\prime}$ & $1^{\prime}, 4^{\prime}$ \\
\hline $4^{\prime}$ & 31.0 & $2.61, \mathrm{qd}(7.4,1.6), 2 \mathrm{H}$ & $3^{\prime}, 5^{\prime}$ & $2^{\prime}, 3^{\prime}, 5^{\prime}, 6^{\prime}$ & 15.4 & $2.13, \mathrm{dd}(7.2,1.9), 3 \mathrm{H}$ & $3^{\prime}$ & $2^{\prime}, 3^{\prime}$ \\
\hline $5^{\prime}$ & 22.3 & 1.46, $\operatorname{sex}(7.4), 2 \mathrm{H}$ & $4^{\prime}, 6^{\prime}$ & $3^{\prime}, 4^{\prime}, 6^{\prime}$ & & & & \\
\hline $6^{\prime}$ & 13.7 & $0.94, \mathrm{t}(7.3), 3 \mathrm{H}$ & $5^{\prime}$ & $4^{\prime}, 5^{\prime}$ & & & & \\
\hline
\end{tabular}

a $\mathrm{HMBC}$ correlations from the proton to the indicated carbon atoms.

lene group, which completed the structure of $\mathbf{4}$ as $O$-isocrotonyl-3-hydroxybutyric acid (Figure 2).

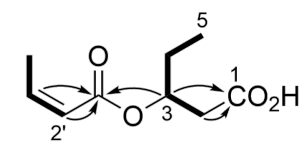

1

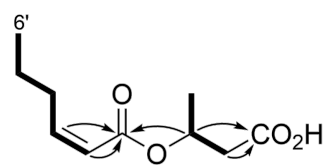

3

Figure 2: COSY (bold lines) and selected HMBC correlations (arrows) for 1-4.

A close similarity of the NMR data for 1-3 (Table 1 and Table 2) allowed the same sequence of structure analysis. The compounds 1 and $\mathbf{2}$ were found to have extra $\mathrm{C}_{1}$ and $\mathrm{C}_{2}$ extensions on the butyric acid units, while in $\mathbf{3}$, an extra $\mathrm{C}_{2}$ extension occurred on the isocrotonyl group, as shown by the connectivity established by the analysis of the COSY spectra (Figure 2). Thus, 1-3 were concluded to be $O$-isocrotonyl-3hydroxypentanoic acid, $O$-isocrotonyl-3-hydroxyhexanoic acid, and $O$-(Z)-2-hexenoyl-3-hydroxybutyric acid, respectively (Figure 1).
A database search identified the planar structure of $\mathbf{4}$ in a patent that described 5 (Figure 1) from marine obligate Vibrio sp. C-984 [9]. To determine the absolute configuration of C3 in 1-4, an anisotropy-based chiral analysis using a chiral derivatization reagent, phenylglycine methyl ester (PGME), was conducted [10]. The compounds $\mathbf{1 - 4}$ were derivatized with $(S)$ - or (R)-PGME by the action of $N, N^{\prime}$-diisopropylcarbodiimide (DIC) and $\mathrm{N}, \mathrm{N}$-dimethylaminopyridine (DMAP) in $\mathrm{CH}_{2} \mathrm{Cl}_{2}$, followed by reversed-phase HPLC to give the respective $(S)$ - or $(R)$-PGME amides 1a, 1b, 2a, 2b, 3a, 3b, 4a, and 4b. The calculation of the ${ }^{1} \mathrm{H}$ NMR chemical shift differences $\Delta \delta_{(S-R)}$ beyond $\mathrm{C} 3$, by subtracting the chemical shift of each proton in the $(R)$-isomer (1b-4b) from those in the $(S)$-isomer $(\mathbf{1 a}-\mathbf{4 a})$, gave positive values at $\mathrm{C} 4, \mathrm{C} 5$, and $\mathrm{C} 6$ and negative values at $\mathrm{C} 2^{\prime}$ and $\mathrm{C} 3$ ' for all four compounds (Figure $3 \mathrm{a}$ ). Note that the sign distribution of the $\Delta \delta_{(S-R)}$ values in $\beta, \beta$-substituted carboxylic acids is inverted from that observed in the $\alpha, \alpha-$ substituted counterparts (Figure $3 b$ ) because the PGME anisotropy group is flipped upside down due to the insertion of an extra methylene group between the chiral center and the carboxylic acid functionality [11]. Thus, the $R$-configuration was concluded for all four compounds 1-4.

The compounds 1-4 are closely related to PHAs, the energy reserve substances for eubacteria and some species of archaea [12]. Both groups of compounds are composed of $(R)$-configured 3-hydroxy fatty acids [13], and 3-hydroxybutyric acid in $\mathbf{3}$ and $\mathbf{4}$ and 3-hydroxyhexanoic acid in $\mathbf{2}$ are the most common two building blocks for PHAs [14]. However, degrees of poly- 
<smiles>COC(=O)C[C@H](C[18O])OC(=O)/C=C/[O-]</smiles>

1

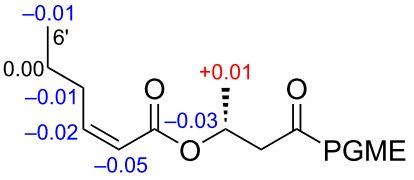

3
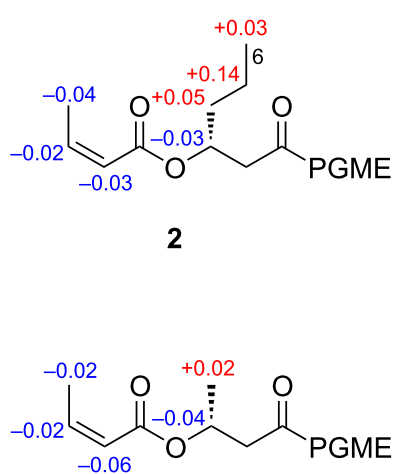

4 b)
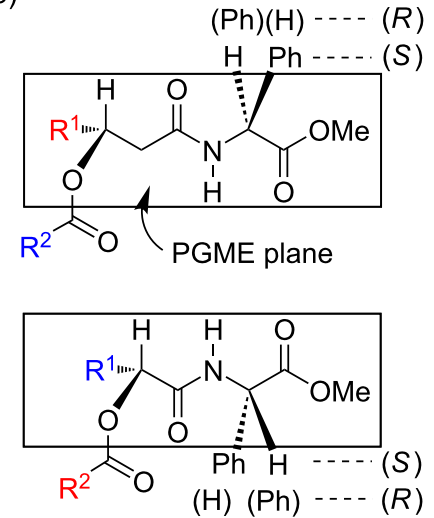

Figure 3: a) Distribution of positive (red) and negative (blue) $\Delta \delta_{(S-R)}$ values (in ppm) calculated from the ${ }^{1} \mathrm{H}$ NMR chemical shifts of the (S)- and (R)-PGME amides of 1-4. b) Comparison of the major conformers of the PGME amide derivatives between the $\beta, \beta$-substituted carboxylic acids (top) and the $\alpha, \alpha$-substituted carboxylic acids (bottom), showing an orientational inversion of the PGME groups.

merization as low as for $\mathbf{1}-\mathbf{4}$ and the dehydrative modifications are unprecedented, besides for $\mathbf{5}$ [9].

Because PHAs are by nature biodegradable, can be produced from renewable bioresources, and have material properties close to the conventional petroleum-derived plastics, the commercial production and market development are actively pursued by several companies amid the growing plastic waste crisis $[14,15]$. Vibrio are perhaps the first to be known as producers of PHAs among marine microbes [16], and are isolated predominantly for the screening of the PHA production [17]. Intriguingly, aquatic farmed animals fed with poly(3-hydroxybutyrate) showed a reduced mortality compared to those not fed when being exposed to pathogenic Vibrio species, suggesting the application of PHAs as a biocontrol agent [18]. Although the toxicity of 1-4 toward the producing strain was not tested, they weakly inhibited the growth of Tenacibaculum maritimum, a causative agent of skin ulcers in marine fish, at MIC values of 25 (1), 50 (2), 50 (3), and $25 \mu \mathrm{g} / \mathrm{mL}$ (4), respectively. None of the compounds showed cytotoxicity against $3 \mathrm{Y} 1$ rat embryonic fibroblastic cells below $50 \mu \mathrm{g} / \mathrm{mL}$.

\section{Conclusion}

In summary, the known $O$-isocrotonyl-3-hydroxybutyric acid (4) and its three new congeners with different alkyl chain lengths, $O$-isocrotonyl-3-hydroxypentanoic acid (1), $O$-isocrotonyl-3-hydroxyhexanoic acid (2), and $O$-(Z)-2hexenoyl-3-hydroxybutyric acid (3), were isolated from the fermentation extract of the sea anemone-derived bacterium of the genus Vibrio. The application of the anisotropy-based chiral analysis unequivocally determined the $(R)$-configuration of the 3-hydroxy acid components in 1-4. These compounds showed no cytotoxicity but were weakly antibacterial against a fish ulcer pathogen, Tenacibaculum maritimum. The (2Z)-enoic acyl termini in $\mathbf{1 - 4}$ are precedented by $\mathbf{5}$, discovered from another Vibrio bacterium, and the $(R)$-configured short-chain 3-hydroxy acids are the common building blocks with PHA, the microbial storage polymer. The structural similarities among 1-5 and PHA suggest a quite similar or even the same biosynthetic origin of these molecules, and hence a potential dehydrative modification at the hydroxy terminus of PHA. MS and NMR analyses combined with state-of-the-art chemical approaches should unveil the detailed structure of PHAs and possibly offer a clue to alter the property of these promising biomaterials.

\section{Experimental General experimental procedures}

Optical rotations were recorded on a JASCO P-1030 polarimeter. UV and IR absorption spectra were recorded on a Shimadzu UV-1800 and a Perkin Elmer Spectrum 100 spectrophotometer, respectively. NMR spectra were obtained on a Bruker AVANCE 500 spectrometer, referencing to the residual solvent peaks at $\delta_{\mathrm{H}} 7.26$ and $\delta_{\mathrm{C}} 77.0$ for $\mathrm{CDCl}_{3}$. HRESIMS-TOF spectra were measured using a Bruker micrOTOF focus mass spectrometer. The absorbance of a formazan solution at $540 \mathrm{~nm}$ was measured on a ThermoFisher Scientific Multiskan Sky microplate reader.

\section{Biological material}

The sea anemone Radianthus crispus was purchased from an aquarium vendor in Nagasaki, Japan. The strain SI9 was isolated from its outer tissue specimen according to the method described previously [19] and identified as a member of the genus Vibrio on the basis of an $98.6 \%$ similarity in the $16 \mathrm{~S}$ rRNA gene sequence (1458 nucleotides; DDBJ accession number LC498627) to Vibrio nereis DSM $19584^{\mathrm{T}}$ (accession number LHPJ01000025). 


\section{Fermentation and isolation of $\mathbf{1 - 4}$}

Colonies of the strain SI9, recovered on a Marine Agar plate, were transferred into a $500 \mathrm{~mL} \mathrm{~K}-1$ flask containing $100 \mathrm{~mL}$ $1 / 3$ strength of simplified Marine Broth, which was prepared from $0.5 \%$ peptone, $0.1 \%$ yeast extract, and $3 \mathrm{~L}$ seawater, with the $\mathrm{pH}$ adjusted to 7.6. After being fermented at $30{ }^{\circ} \mathrm{C}$ at $200 \mathrm{rpm}$ for 2 days, $3 \mathrm{~mL}$ aliquots of the seed culture thus prepared were dispensed into $500 \mathrm{~mL} \mathrm{~K}-1$ flasks, each containing $100 \mathrm{~mL}$ A16 production medium consisting of $2 \%$ glucose, $1 \%$ Pharmamedia, $0.5 \% \mathrm{CaCO}_{3}$ and $1 \%$ Diaion $\mathrm{HP}-20$ in natural seawater. After being shake-cultured at $30{ }^{\circ} \mathrm{C}$ at $200 \mathrm{rpm}$ for 5 days, each production culture received $100 \mathrm{~mL} n$-butanol, and the flasks were shaken for an additional $1 \mathrm{~h}$ for extraction. The emulsified broth was centrifuged at $6000 \mathrm{rpm}$ for $10 \mathrm{~min}$, and the resulting butanol layers were collected and concentrated in vacuo to give $5.8 \mathrm{~g}$ of an extract from a $3 \mathrm{~L}$ culture. This was first fractionated on a silica gel column with a stepwise elution by $\mathrm{CHCl}_{3} / \mathrm{MeOH}$ mixtures $(1: 0,20: 1,10: 1,4: 1,2: 1,1: 1$, and $0: 1, \mathrm{v} / \mathrm{v})$. The third fraction $(1.35 \mathrm{~g})$ was further fractionated by ODS column chromatography, eluting with $\mathrm{MeCN} / 0.1 \%$ $\mathrm{HCOOH}(2: 8,3: 7,4: 6,5: 5,6: 4,7: 3$, and 8:2, v/v). The fourth fraction $(0.28 \mathrm{~g})$ was subjected to reversed-phase HPLC on a Cosmosil AR-II column $(10 \times 250 \mathrm{~mm})$, eluting with $32 \%$ $\mathrm{MeCN}$ in $0.1 \% \mathrm{HCOOH}$ at $4 \mathrm{~mL} / \mathrm{min}$ to give $1\left(1.5 \mathrm{mg} ; t_{\mathrm{R}}\right.$ $16.1 \mathrm{~min}), 2\left(11.2 \mathrm{mg} ; t_{\mathrm{R}} 17.6 \mathrm{~min}\right), \mathbf{3}\left(4.3 \mathrm{mg} ; t_{\mathrm{R}} 18.3 \mathrm{~min}\right)$, and $4\left(135.6 \mathrm{mg} ; t_{\mathrm{R}} 9.8 \mathrm{~min}\right)$.

\section{Preparation of the $(S)$ - and $(R)$-phenylglycine methyl ester amides}

To a solution of $4(1.7 \mathrm{mg}, 10 \mu \mathrm{mol})$ in anhydrous $\mathrm{CH}_{2} \mathrm{Cl}_{2}$ $(0.5 \mathrm{~mL})$ in a dried vial were added $(S)$-phenylglycine methyl ester (PGME, $3.3 \mathrm{mg}, 16.4 \mu \mathrm{mol})$, DMAP (1.2 mg, $10 \mu \mathrm{M}$ ), and DIC $(3.0 \mu \mathrm{L}, 19.5 \mu \mathrm{mol})$, and the mixture was stirred for $30 \mathrm{~min}$ at room temperature. The production of the amide was monitored by thin-layer chromatography (TLC), developed using ethyl acetate/ $n$-hexane $1: 1$, followed by heating with phosphomolybdic acid. After removing the solvent, the residue was subjected to HPLC on a Cosmosil $\pi$-NAP column $(10 \times 250 \mathrm{~mm})$, eluted by a gradient method $(\mathrm{MeCN} / 0.1 \% \mathrm{HCOOH})$ at $4 \mathrm{~mL} / \mathrm{min}$, with monitoring at $254 \mathrm{~nm}$, to give the $(S)$-PGME amide $4 \mathbf{a}(2.9 \mathrm{mg}, 93 \%)$ as colorless oil.

The PGME amides $\mathbf{1 a} / \mathbf{b}-\mathbf{3 a} / \mathbf{b}$ and $\mathbf{4 b}$ were prepared by the same procedure but replacing the starting material and the chiral reagent accordingly.

\section{Antibacterial assay}

The antibacterial activity was evaluated by a microculture technique described previously [20], except for a 1:100 reduction of the seeding density of T. maritimum NBRC16015.

\section{Cytotoxicity assay}

3Y1 rat embryonic fibroblastic cells were maintained in lowglucose DMEM medium containing L-glutamine and phenol red (Fujifilm Wako Pure Chemical, 041-29775), supplemented with $10 \%$ fatal bovine serum, 100 units $/ \mathrm{mL}$ penicillin, $100 \mu \mathrm{g} / \mathrm{mL}$ streptomycin, $0.25 \mu \mathrm{g} / \mathrm{mL}$ amphotericin B (Fujifilm Wako Pure Chemical, 161-23181), and $100 \mu \mathrm{g} / \mathrm{mL}$ gentamicin sulfate (Fujifilm Wako Pure Chemical, 078-06061). The cells were seeded in each well of a 96-well culture plate at a density of 2500 cells/ well. Meanwhile, the compounds 1-4 and doxorubicin hydrochloride as a positive control were serially diluted 1:3.16 (halflog dilution) by the same medium in a different microtiter plate. After incubating the cell culture for $12 \mathrm{~h}$ at $37{ }^{\circ} \mathrm{C}$ in an atmosphere of $95 \%$ air and $5 \% \mathrm{CO}_{2}$ saturated with $\mathrm{H}_{2} \mathrm{O}$, the drug solutions were transferred into each cell culture to make up $200 \mu \mathrm{L}$ of the culture. The highest concentration of the vehicle solvents (MeOH or DMSO) was set at 0.5 vol \%, where the growth of the cells was not affected. After incubating the test plate for $84 \mathrm{~h}, 100 \mu \mathrm{L}$ of the medium containing MTT $1 \mathrm{mg} / \mathrm{mL}$ was added to each well, and the plate was further incubated for $4 \mathrm{~h}$. The medium was carefully removed by aspiration, and formazan dye formed at the bottom of the wells was solubilized by the addition of $150 \mu \mathrm{L}$ DMSO. The respiration of live cells was quantified by the measurement of the absorption at $540 \mathrm{~nm}$ by a microplate reader. The experiment was run in a triplicate, and the rates of the cell-growth inhibition at each concentration were plotted on a single logarithmic chart to deduce the $\mathrm{GI}_{50}$ values of the test compounds.

\section{Supporting Information}

\section{Supporting Information File 1}

Spectra and compound characterization data for $\mathbf{1 - 4}$ and the PGME amide pairs $\mathbf{1 a} / \mathbf{b}-\mathbf{4} \mathbf{a} / \mathbf{b}$.

[https://www.beilstein-journals.org/bjoc/content/ supplementary/1860-5397-16-154-S1.pdf]

\section{Acknowledgements}

We thank Profs. Shinichi Ikushiro and Miyu Nishikawa for allowing and instructing us to use the Multiskan Sky microplate reader. Tenacibaculum maritimum NBRC16015 and 3Y1 cells were obtained from the Biotechnology Resource Center, National Institute of Technology and Evaluation and the JCRB Cell Bank, National Institute of Biomedical Innovation, Health and Nutrition, respectively.

\section{Funding}

This work was supported in part by JSPS KAKENHI Grant Number JP19K05848 to Y. I and JP18K05827 to N. O. 


\section{ORCID ${ }^{\circledR}$ iDs}

Dandan Li - https://orcid.org/0000-0002-0384-989X Enjuro Harunari - https://orcid.org/0000-0001-8726-0865 Tao Zhou - https://orcid.org/0000-0002-6359-2598 Naoya Oku - https://orcid.org/0000-0002-2171-2168 Yasuhiro Igarashi - https://orcid.org/0000-0001-5114-1389

\section{Preprint}

A non-peer-reviewed version of this article has been previously published as a preprint doi:10.3762/bxiv.2020.54.v1

\section{References}

1. Farmer, J. J., III; Janda, J. M.; Brenner, F. W.; Cameron, D. N. Birkhead, K. M. Vibrio. In Bergey's Manual of Systematics of Archaea and Bacteria; Whitman, W. B., Ed.; John Wiley \& Sons: Hoboken, NJ, U.S.A., 2015; pp 1-79. doi:10.1002/9781118960608.gbm01078

2. Parte, A. C. Int. J. Syst. Evol. Microbiol. 2018, 68, 1825-1829. doi:10.1099/ijsem.0.002786

3. Mohamad, N.; Amal, M. N. A.; Yasin, I. S. M.; Zamri Saad, M.; Nasruddin, N. S.; Al-saari, N.; Mino, S.; Sawabe, T. Aquaculture 2019, 512, 734289. doi:10.1016/j.aquaculture.2019.734289

4. Ceccarelli, D.; Amaro, C.; Romalde, J. L.; Suffredini, E.; Vezzulli, L. Vibrio Species. In Food Microbiology: Fundamentals and Frontiers, 5th ed.; Doyle, M. P.; Diez-Gonzalez, F.; Hill, C., Eds.; ASM Press: Washington, DC, U.S.A., 2019; pp 347-388. doi:10.1128/9781555819972.ch13

5. Kang, S. R.; Srinivasan, S.; Lee, S.-S. Int. J. Syst. Evol. Microbiol. 2015, 65, 3552-3557. doi:10.1099/ijsem.0.000456

6. Gómez-Consarnau, L.; Akram, N.; Lindell, K.; Pedersen, A.; Neutze, R.; Milton, D. L.; González, J. M.; Pinhassi, J. PLoS Biol. 2010 8, e1000358. doi:10.1371/journal.pbio.1000358

7. Gutierrez, C. K.; Matsui, G. Y.; Lincoln, D. E.; Lovell, C. R. Appl. Environ. Microbiol. 2009, 75, 2253-2258. doi:10.1128/aem.02072-08

8. Dictionary of Natural Products 28.2 Chemical Search. http://dnp.chemnetbase.com/faces/chemical/ChemicalSearch.xhtml (accessed April 14, 2020).

9. Kikuchi, K.; Chen, C.; Takadera, T.; Nishijima, M.; Araki, M.; Adachi, K.; Sano, H. New 3-hydroxybutyric acid oligomers and their preparation. JP Patent 104,991, Jan 18, 1998.

10. Nagai, Y.; Kusumi, T. Tetrahedron Lett. 1995, 36, 1853-1856. doi:10.1016/0040-4039(95)00132-v

11. Yabuuchi, T.; Kusumi, T. J. Org. Chem. 2000, 65, 397-404. doi:10.1021/jo991218a

12. Rehm, B. H. A. Biochem. J. 2003, 376, 15-33. doi:10.1042/bj20031254

13. Kaunzinger, A.; Podebrad, F.; Liske, R.; Maas, B.; Dietrich, A.; Mosandl, A. J. High Resolut. Chromatogr. 1995, 18, 49-53. doi:10.1002/jhrc.1240180111

14. Choi, S. Y.; Rhie, M. N.; Kim, H. T.; Joo, J. C.; Cho, I. J.; Son, J.; Jo, S. Y.; Sohn, Y. J.; Baritugo, K.-A.; Pyo, J.; Lee, Y.; Lee, S. Y.; Park, S. J. Metab. Eng. 2020, 58, 47-81. doi:10.1016/j.ymben.2019.05.009

15. Tullo, A. H. Chem. Eng. News 2019, 97 (35), 20-21. doi:10.1021/cen-09735-feature2

16. Baumann, P.; Baumann, L.; Mandel, M. J. Bacteriol. 1971, 107, 268-294. doi:10.1128/jb.107.1.268-294.1971
17. Kavitha, G.; Rengasamy, R.; Inbakandan, D. Int. J. Biol. Macromol. 2018, 111, 102-108. doi:10.1016/j.ijbiomac.2017.12.155

18. Laranja, J. L. Q.; Bossier, P. Poly-beta-hydroxybutyrate (PHB) and infection reduction in farmed aquatic animals. In Health Consequences of Microbial Interactions with Hydrocarbons, Oils, and Lipids; Goldfine, H., Ed.; Springer International Publishing: Cham, Switzerland 2019; pp 1-27. doi:10.1007/978-3-319-72473-7_35-1

19. Sharma, A. R.; Zhou, T.; Harunari, E.; Oku, N.; Trianto, A.; Igarashi, Y. J. Antibiot. 2019, 72, 634-639. doi:10.1038/s41429-019-0192-x

20. Oku, N.; Matsumoto, M.; Yonejima, K.; Tansei, K.; Igarashi, Y. Beilstein J. Org. Chem. 2014, 10, 1808-1816. doi:10.3762/bjoc.10.190

\section{License and Terms}

This is an Open Access article under the terms of the Creative Commons Attribution License

(http://creativecommons.org/licenses/by/4.0). Please note that the reuse, redistribution and reproduction in particular requires that the authors and source are credited.

The license is subject to the Beilstein Journal of Organic Chemistry terms and conditions: (https://www.beilstein-journals.org/bjoc)

The definitive version of this article is the electronic one which can be found at: doi: $10.3762 /$ bjoc. 16.154 